\title{
Use of Movable Bus Stop Loading Pads: Feasibility and Design Alternatives
}

\author{
Nakin Suksawang, Ph.D., P.E., Florida Institute of Technology \\ Priyanka Alluri, Ph.D., P.E., Albert Gan, Ph.D., Katrina Meneses, M.S., \\ Fabian Cevallos, Ph.D., Kirolos Haleem, Ph.D., P.E., PTOE, Dibakar Saha, M.S. \\ Florida International University
}

\begin{abstract}
The Americans with Disabilities Act (ADA) of 1990 requires bus stops to be accessible for individuals with disabilities. At a minimum, bus stops must have firm, stable, slip-resistant loading pads with connected sidewalks and curb ramps. Consequently, the typical approach of transit agencies has been to install permanent concrete loading pads at bus stops. This study explored alternatives to conventional concrete pads with movable pads that could be installed quickly, resulting in savings in construction and labor costs and minimizing both disruptions to traffic and impacts to abutting businesses. Potential design alternatives in terms of materials and structural support for these pads were evaluated. The review focused on existing and alternative design materials, especially in applications other than for transit purposes. Six materials were evaluated based on their structural performance, long-term durability, adaptability, life cycle cost, aesthetics, and safety and accessibility of transit riders with mobility devices. Of the six materials, plastic lumber and metal were found to have the highest potential to replace conventional designs. Two design alternatives that rely on the concept of bridge construction were introduced, both of which consist of four major components: foundation, slab, beam, and connections. These new design alternatives are anticipated to minimize maintenance of traffic and the need for heavy machinery to excavate, fill, and/or compact the soil.
\end{abstract}

\section{Introduction}

Bus stops are key links in the journeys of transit riders, particularly for individuals with disabilities. Because of physical, sensory, or mental challenges, people with disabilities often rely on public transportation as their primary source of transportation. However, inaccessible bus stops often prevent them from using fixed-route bus services, forcing them to use the more expensive paratransit services. A bus stop can be deemed inaccessible because of the lack of a firm, stable, slip-resistant loading pads with connected sidewalks and curb ramps (Wu et al. 2011). 
The Americans with Disabilities Act (ADA) of 1990 implementing guidelines prescribe the minimum requirements for bus stop accessibility for riders with disabilities. Figure 1 illustrates the ADA minimum standards for bus stop loading areas. As shown, the standards require a firm, stable, slip-resistant loading pad $5^{\prime}$ wide by $8^{\prime}$ deep with connected sidewalks of $3^{\prime}$ clear passage width, 1:50 (2\%) maximum cross slope, and 1:12 (8.33\%) curb cut slope. While not mandated by ADA, a $5^{\prime}$ construction width (with a $3^{\prime}$ clear passage width) is preferred for sidewalks to accommodate patrons with physical disabilities (U.S. Access Board 2006).

FIGURE 1.

Minimum requirements for ADA-compliant bus stops

(Wu et al. 2011)

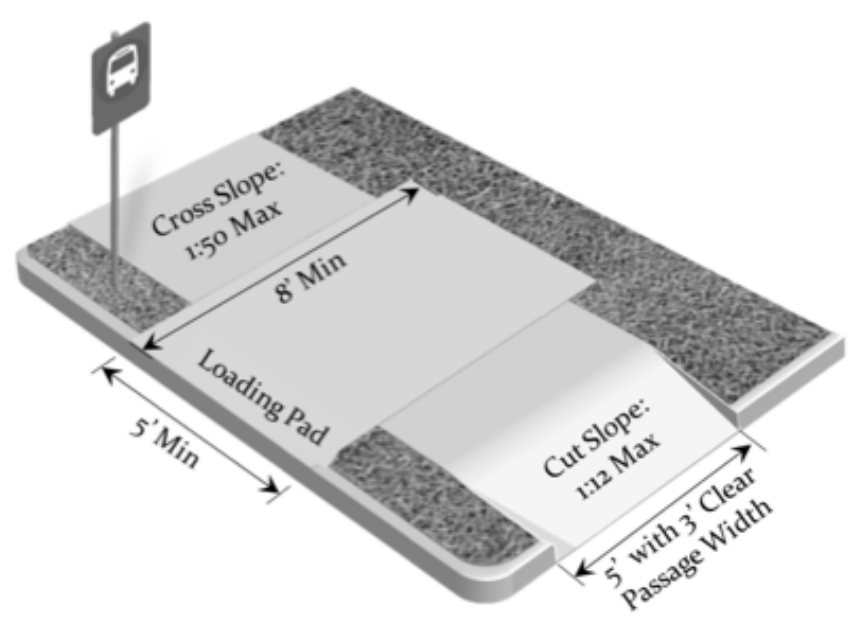

To meet ADA requirements, transit agencies usually install permanent concrete loading pads at their bus stops. However, often, economic conditions may cause transit agencies to discontinue or reconfigure routes to reduce costs and maximize system efficiencies. Services along particular routes, when terminated or relocated, leave in place permanent bus stop features such as the concrete pad along a roadway right-of-way. Often, transit agencies are required to remove loading pads from discontinued bus stop locations. Additionally, new concrete loading pads may be required at new bus stops along a newly-relocated transit route if service along the corridor was not provided previously. The installation and removal of these permanent features can be costly to transit agencies and/or local governments. Considering that most urbanized transit agencies have thousands of bus stops, the number of stops that may need to be removed, added, or relocated can be significant and could represent a significant annual expenditure.

Concrete slabs, which are both costly to install and non-reusable, are not specifically required to meet ADA requirements. Section 810.2.1 of the latest version of the Americans with Disabilities Act Accessibility Guidelines (ADAAG), as amended in 2006, states that "bus stop boarding and alighting areas shall have a firm, stable surface." As part of the requirements for Accessible Routes under Section 403.2 of ADAAG, it further requires that the surface be "slip-resistant." While the conditions that qualify a surface as firm, stable, and slip-resistant have not been defined, a supplemental document called A Guide to ADAAG Provisions, published by U.S. Access Board, states that "accessible routes do not necessarily have to be paved, but must be firm, stable, and slip-resistant so that they are safe and usable by people who use wheelchairs or who walk with difficulty" (U.S. Access 
Board 2006). This guidance is especially important, as it clearly provides a basis for using materials other than a paved surface for bus stop loading pads.

This paper summarizes the results from a study by the Florida Department of Transportation (FDOT) to explore alternatives to conventional concrete pads with the use of portable bus stop pads that could be installed quickly, resulting in savings in construction and labor costs and minimizing both disruptions to traffic and impacts to abutting businesses. The FDOT-sponsored research limits itself to the installation of concrete bus stop pads at locations where gaps exist between roadway curbs and parallel sidewalks in areas of flat terrain with minimal or no drainage swales.

This paper includes two focuses: 1) evaluating the existing non-traditional materials for potential use in constructing bus stop loading pads, and 2) developing structural design alternatives for the selected material alternatives (Suksawang et al. 2013). The paper first provides the results from the national survey of transit agencies that focused on agency opinions on the feasibility of using movable ADA-compliant bus stop loading pads.

\section{National Survey of Transit Agencies}

A national survey on the use of movable bus stop pads was designed and conducted. The survey included a total of 18 questions and was distributed to transit agencies via email. A total of 84 transit agencies from across the U.S. responded to the survey. The following are the key relevant findings from the survey responses:

- The main criteria for prioritizing bus stops for ADA improvements include high ridership stops; accessibility; rider complaints and requests; presence of ADAcompliant landing pads, accessible pathways, and curb ramps; availability of right-ofway; roadway improvements; high concentration of disability passengers; and safety.

- Material installation, excavation and maintenance, labor, and maintenance of traffic are the major line items for constructing bus stop pads. Among the major line items associated with installing movable pads, sidewalk replacement has the highest average cost, followed by handicap ramp installation, labor, and maintenance of traffic.

- About 40 percent of the responding agencies (32 of 84 agencies) stated that they change bus routes at least once a year; the main reasons for changing bus routes are changes in passenger demand, requests made by jurisdictions and customers, construction issues and roadway closures, commercial development, time savings, and revenue increases.

- The main reasons for changing bus stop locations include safety concerns, municipality requests, complaints by homeowners, lack of accessibility, changes in passenger ridership, roadway improvements, vandalism, and funding issues/budget cuts.

- Lower installation and maintenance cost, ease of installation and use, time savings, flexibility, portability, and passenger accessibility are the main reasons for preferring movable bus stop pads. 
- The main limitations with using movable bus stop pads include lower durability, strength, and stability; greater risk of theft; weather issues; space limitations; safety and aesthetic issues; and ability to conform to different geographic conditions.

\section{Review of Potential Design Materials}

This section focuses on reviewing and evaluating alternative design materials that could be used for constructing bus stop pads. Materials that are being used in other transportation applications that have characteristics suitable for ADA-compliant bus stop pads are reviewed in detail. The following six categories of materials were reviewed and evaluated for potential use as bus stop pads: (1) concrete/asphalt, (2) metal, (3) rubber, (4) thermoplastic, (5) composite, and (6) wood.

\section{Concrete and Asphalt Materials}

Concrete and asphalt are the two most widely-used materials for constructing sidewalks. They provide excellent durability and can be cast-in-place in various shapes and sizes. Moreover, they can aesthetically blend in with the existing sidewalk and roadway and have minimal maintenance requirements. Due to these factors, concrete and asphalt are the preferred materials for constructing bus stop pads. Despite these advantages, one problem with the use of these materials is the related construction and demolition time. To construct concrete pads, a concrete mixer truck is needed and, depending on the size of the pads, maintenance of traffic may be required, adding to the overall construction cost. The same applies to asphalt pads, for which an asphalt truck and a compacter are needed at the jobsite. Removing concrete or asphalt pads can be expensive since the pads will need to be demolished and hauled away and the site returned to original conditions.

\section{Metallic Materials}

Metals such as steel and aluminum have been used in various products such as railings, poles, and beams. However, they are rarely used in constructing flat slabs because they are expensive and have a smooth surface that is not slip-resistant. Nevertheless, they often are used in flat slabs as a cover plate for manholes, as a temporary cover for trenches, and on special platforms. However, to be used as bus stop pads, the surface of these metals has to be roughened.

\section{Rubber Materials}

Rubber materials have been used in the construction industry for many years and are used with concrete/asphalt products to lower the cost. Rubber materials are also used for speed bumps as well as for providing traction on various smooth surfaces. One clear advantage of rubber products is their weight and price. Further, depending on the type of the product, rubber is often low-maintenance, low-cost, reusable, and durable. Rubber materials also have the ability to withstand all types of conditions.

\section{Thermoplastic Materials}

Thermoplastic materials typically are used as cladding and non-structural components in construction. However, their use has increased in the railroad industry, particularly with railroad tiles; the existing timber tiles have been replaced with plastic lumber. Plastic lumber has been used to replace timber boardwalks and sea walls. It gives a natural look to the area and is relatively maintenance free, and it does not rot, crack, or splinter like wood. 


\section{Composite Materials}

Composite materials such as carbon fiber reinforced polymer have been used for many years by departments of transportation for repairing bridges. These materials have very good durability but are very expensive. However, at least one product, Mobi-Mat, has the potential to be used for bus stop pads. The Mobi-Mat helipad has characteristics suitable for a bus stop pad, with low-level assembly and reuse; therefore, it is a good alternative to existing bus stop pads. The Mobi-Mat is a lightweight, easy-to-handle matting system that can sustain helicopter loads (Deschamps 2013).

\section{Wood Materials}

As an engineering product with very good structural performance, wood has been used in many types of structures. However, wood is not recommended in humid regions, as rain accelerates its deterioration. Since bus stop pads are directly in contact with soil, using wood is not acceptable without having to endure continual maintenance cost.

\section{Evaluation of Potential Design Materials}

This section focuses on evaluating the above-discussed materials for their potential use as bus stop pads. Table 1 provides the rating (on a scale of $1=$ worst to $5=$ best) of each of the following six criteria for the six materials:

1. Structural performance

2. Long-term durability

3. Adaptability

4. Life cycle cost

5. Aesthetics

6. Safety and accessibility of transit riders with mobility devices

TABLE 1. Evaluation of Materials for Potential Use as Bus Stop Pads

\begin{tabular}{|c|c|c|c|c|c|c|c|}
\hline \multirow[b]{2}{*}{ Material } & \multirow{2}{*}{$\begin{array}{l}\text { Commercially } \\
\text { Available Product }\end{array}$} & \multicolumn{6}{|c|}{ Rating $^{1}$} \\
\hline & & $\begin{array}{c}\text { Structural } \\
\text { Performance }\end{array}$ & $\begin{array}{l}\text { Long-Term } \\
\text { Durability }\end{array}$ & Adaptability & Life Cycle Cost & Aesthetics & $\begin{array}{l}\text { Safety and } \\
\text { Accessibility }\end{array}$ \\
\hline \multirow{2}{*}{$\begin{array}{l}\text { Concrete/ } \\
\text { Asphalt }\end{array}$} & Asphalt pad & 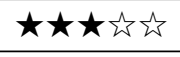 & 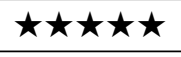 & 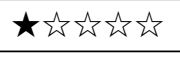 & 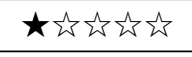 & 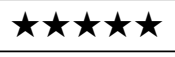 & 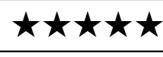 \\
\hline & Concrete pad & $\star \star \star \star \star \star え$ & 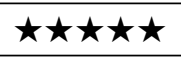 & 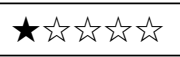 & 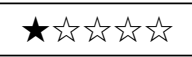 & 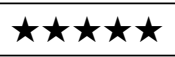 & 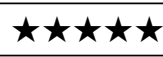 \\
\hline \multirow{2}{*}{ Metal } & Steel & 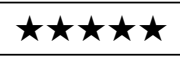 & 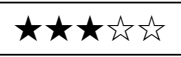 & 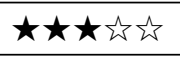 & 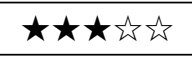 & 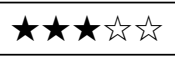 & 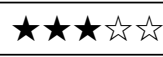 \\
\hline & Aluminum & 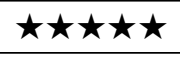 & 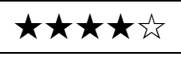 & 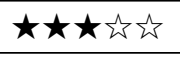 & $\star \star \star \star \star え え$ & 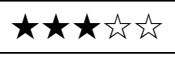 & 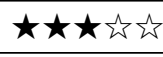 \\
\hline \multirow{2}{*}{ Rubber } & Flexi-Pave $^{2}$ & \multirow{2}{*}{ 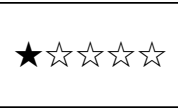 } & \multirow{2}{*}{ 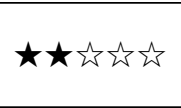 } & \multirow{2}{*}{ 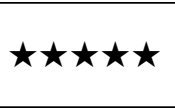 } & \multirow{2}{*}{ 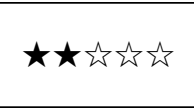 } & \multirow{2}{*}{ 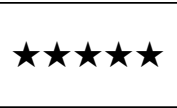 } & \multirow{2}{*}{ 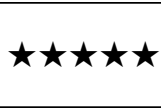 } \\
\hline & Rubber crosswalk & & & & & & \\
\hline Thermo- plastic & Plastic lumber & 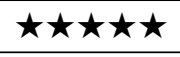 & 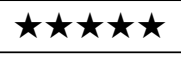 & 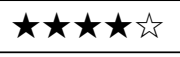 & 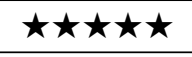 & 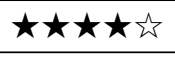 & $\star \star \star \star \star え 乞$ \\
\hline Composite & Mobi-Mat & 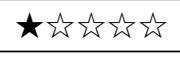 & 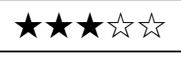 & 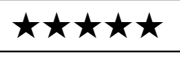 & 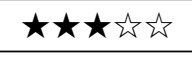 & 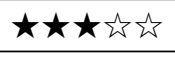 & 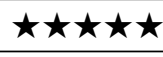 \\
\hline Wood & Roll-out walkway & 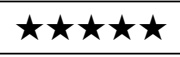 & 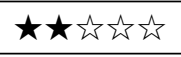 & 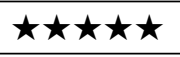 & 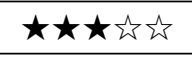 & 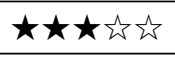 & $\star \star \star \star \star \star え$ \\
\hline
\end{tabular}


The structural performance criterion is based on the strength, rigidity, and toughness of the material, i.e., the material's ability to plastically deform without fracture. Metals perform the best in this category; however, since bus stop pads typically will experience foot traffic, all the materials did well, with the exception of rubber and composite materials, which received a rating of $1 / 5$ since both rely on the strength of the sub-base. Should the sub-base not be compacted properly or a settlement occurs to the sub-base, both rubber and composite pads will deform in the same manner as the sub-base.

Long-term durability is a material's ability to resist scratches and the harsh outdoor environment. Concrete/asphalt, metals, and plastic lumber perform well, with a rating of 5/5, $4 / 5$, and $5 / 5$, respectively. Wood did not perform as well, since it could deteriorate more rapidly in humid conditions. For this reason, wood is not recommended for a bus stop pad despite its relatively good life cycle cost (as discussed in the later sections).

The adaptability criterion evaluated the material's ability to be modified and adjusted to fit with the various site conditions present at bus stops. Overall, all materials, with the exception of concrete, can be easily cut and adjusted onsite.

Life cycle cost included the overall costs of the material over a period of 50 years by considering the initial, maintenance, relocation, and demolition costs as well as the cost associated with the frequent relocation of bus stops. However, it does not include the costs associated with mobilization, excavation, maintenance of traffic, etc. Overall, plastic lumber has the lowest life cycle cost if the pads need to be removed, relocated, and reused frequently. Conventional concrete/asphalt pads have the highest life cycle cost if the frequency of route changes is at least once per year. However, conventional concrete/ asphalt pads have the lowest initial cost. The next section provides a detailed discussion on the life cycle costs.

The aesthetics of the material depends on its color and its ability to blend in with the existing infrastructure such as sidewalks. Overall, all materials can be coated or manufactured to match the color of the existing sidewalk; therefore, aesthetics should not be a main concern in material selection. However, it should be noted that coating could reduce the material's service life and, therefore, proper coating should be carefully selected to ensure the longevity of the materials.

The safety and accessibility of transit riders with mobility devices is a very important criterion. Most of the materials, whether precast concrete, steel, or plastic lumber, likely will be assembled onsite. This will result in small gaps between the assemblies, which could be a problem for individuals with canes or other mobility devices, as they could get stuck in the gaps. As long as the assemblies are properly designed, the safety and accessibility of persons with mobility devices should not be of a concern. According to ADA, the maximum permissible gap is $1 / 2^{\prime \prime}$. The gap, if greater than $1 / 2$ ", also could be filled with rubber pads. Therefore, this should not be a problem in terms of safety and accessibility for these materials.

Per the above discussion, plastic lumber is considered to have the highest potential to replace the conventional design based on design considerations, material properties, and life cycle cost. It has good strength (although not as high as concrete), and it is also con- 
siderably light (although not as light as Mobi-mat). Plastic lumber is also one of the least expensive and most durable systems.

\section{Life Cycle Cost}

Life cycle cost is estimated by considering five main factors: 1) initial cost, 2) maintenance cost, 3) reconstruction cost, 4) demolition/recondition cost, and 5) cost associated with frequent route changes. However, it does not include the costs associated with mobilization, excavation, maintenance of traffic, etc. The formula used to calculate the total life cycle cost is shown below as Equation 1. The total life cycle cost is calculated based on a 50-year service life of the $5^{\prime} \times 8^{\prime}$ bus stop pad.

$$
T C=I C+(M C \times 50 y r s)+\left[(R C+D C) \times \frac{50 y r s}{\text { freq. of relocations per year }}\right]
$$

where $T C$ is total cost, $I C$ is initial cost, $M C$ is maintenance cost, $R C$ is reconstruction cost, and $D C$ is demolition cost.

Initial cost consists of material and labor costs that are based on historical costs obtained from the 2011 FDOT Annual Statewide Averages (FDOT 2011). In the case of alternative products with no historical data such as Mobi-mat, their actual market prices are used. Besides the material and labor costs, other associated costs such as site preparation and maintenance of traffic are not considered in the evaluation process because of the complexity and variability in the sites.

Maintenance cost is an annual estimate based on a material's long-term performance and manufacturer warranties. As described earlier, traditional materials such as concrete, aluminum, and steel do not require maintenance since the bus stop pads experience only foot traffic. The maintenance costs for rubber, thermoplastic, and wood materials are based on manufacturer warranty for the products. For example, the average warranty of treated wood is 15 years, which means the system might need to be replaced in 15 years. Therefore, the annual maintenance cost is calculated by taking the initial cost divided by the number of years of warranty (i.e., 15 in this example). Plastic lumber has a good track record of performing over 50 years and, therefore, there is no associated maintenance cost.

Reconstruction cost is the cost needed for moving an existing bus stop pad to a new site. For a conventional concrete/asphalt pad, a new pad has to be reconstructed since the existing pad cannot be salvaged. In the case of wood, it is anticipated that during the removal process of the existing pad, only a fraction of the materials can be salvaged. As for wood, some planks might warp over time, and the wood at the fastened location also could split during the removal process.

Demolition/recondition cost is the cost associated with demolishing the existing bus stop pad (as in the case of a conventional pad) and reconditioning the top soil to its original condition. In most cases, reconditioning involves growing grass in place of the existing pad. The frequency of route changes was analyzed for once every five years and once per year. 
Table 2 summarizes the cost comparison of various materials based on the construction of a $5^{\prime} \times 8^{\prime}$ bus stop pad. From the table, it is clear that plastic lumber has the lowest cost, regardless of the frequency at which the bus route changes. The precast concrete system is second lowest, with the lowest life cycle cost despite its high initial cost. The precast concrete option could be cost-effective if the weight of the precast concrete section is low enough that it can be hand-carried without the use of equipment. Conventional concrete/asphalt pads have the lowest initial and maintenance costs. However, they become the most expensive option if the bus stop has to be relocated at least once per year. If the route changes are less frequent, i.e., once in every five years, then the conventional concrete/asphalt pad is quite cost-effective, followed by plastic lumber.

TABLE 2. Cost Comparison of Potential Design Materials

\begin{tabular}{|c|c|c|c|c|c|c|c|}
\hline Material & $\begin{array}{l}\text { Commercially } \\
\text { Available Product }\end{array}$ & $\begin{array}{c}\text { Initial } \\
\text { Cost }\end{array}$ & $\begin{array}{c}\text { Maintenance } \\
\text { Cost }\end{array}$ & $\begin{array}{c}\text { Reconstruction } \\
\text { Cost }\end{array}$ & $\begin{array}{l}\text { Demolition/ } \\
\text { Recondition } \\
\text { Cost }\end{array}$ & $\begin{array}{c}\text { Cost when Route } \\
\text { Changes Once } \\
\text { Every } 5 \text { Years }\end{array}$ & $\begin{array}{l}\text { Cost when } \\
\text { Route Changes } \\
\text { Once per Year }\end{array}$ \\
\hline \multirow{2}{*}{$\begin{array}{l}\text { Concrete/ } \\
\text { Asphalt }\end{array}$} & Concrete/ asphalt pad & $\$ 188$ & $\$ 0$ & $\$ 188$ & $\$ 65$ & $\$ 2,724$ & $\$ 12,866$ \\
\hline & Precast system & $\$ 1,224$ & $\$ 0$ & $\$ 0$ & $\$ 19$ & $\$ 1,415$ & $\$ 2,181$ \\
\hline \multirow{2}{*}{ Metal } & Steel plate & $\$ 2,742$ & $\$ 0$ & $\$ 0$ & $\$ 11$ & $\$ 2,857$ & $\$ 3,315$ \\
\hline & Aluminum plate & $\$ 3,400$ & $\$ 0$ & $\$ 0$ & $\$ 10$ & $\$ 3,499$ & $\$ 3,896$ \\
\hline \multirow{2}{*}{ Rubber } & Flexi-Pave $^{1}$ & $\$ 240$ & $\$ 48$ & $\$ 0$ & $\$ 34$ & $\$ 2,985$ & $\$ 4,364$ \\
\hline & Rubber crosswalk & $\$ 1,000$ & $\$ 67$ & $\$ 0$ & $\$ 10$ & $\$ 4,433$ & $\$ 4,829$ \\
\hline Thermo-plastic & Plastic lumber & $\$ 673$ & $\$ 0$ & $\$ 0$ & $\$ 11$ & $\$ 787$ & $\$ 1,245$ \\
\hline Composite & Mobi-Mat & $\$ 900$ & $\$ 45$ & $\$ 0$ & $\$ 10$ & $\$ 3,249$ & $\$ 3,646$ \\
\hline Wood & Roll-out walkway & $\$ 301$ & $\$ 20$ & $\$ 30$ & $\$ 11$ & $\$ 1,718$ & $\$ 3,378$ \\
\hline
\end{tabular}

${ }^{1}$ Flexi-Pave is a rubber granule material that is bounded with a urethane agent to make a flexible, porous, non-cracking, and slip-resistant surface.

Metals, particularly steel, also have lower life cycle costs if the transit agencies anticipate at least one route change per year. Wood is also not a bad option if frequent route changes are not anticipated by the transit agency. However, wood is not recommended in humid regions. Besides wood, the conventional concrete/asphalt pad would be better suited when frequent route changes are not anticipated. Since the existing rubber and composite products currently are not designed to be permanently installed outdoors, their associated maintenance cost is too high for them to be considered as viable options for bus stop pads.

\section{Design of Bus Stop Pads}

This section focuses on the development of a full system integration and installation of bus stop pads using plastic lumber and metal systems. The following four components of the installation process are discussed in detail for both plastic lumber and metallic pads: foundation, slab, supporting beam, and connections.

Plastic lumber is the only non-traditional material (traditional materials consist of concrete, asphalt, and steel) that has a sufficient track record, including both research and field experience by the railroad industry, Department of Defense, and Federal Highway 
Administration. In addition to plastic lumber, metallic material also could be used in designing bus stop pads. Although metal is more expensive than plastic lumber, construction using metal is significantly quicker and potentially could provide cost savings if transit agencies anticipate frequent route changes.

\section{Preliminary Design Concept}

To develop a framework for the proposed pads, existing site conditions-ranging from narrow to wide depths and hard to soft bases-were considered. One of the biggest challenges for designing the pads is to design an easily-adaptable structural component that requires little maintenance of traffic. To this end, the following two options were proposed: 1) plastic lumber pads and 2) metallic pads.

A plastic lumber pad is similar to the type used for constructing outdoor decks or boardwalks. The challenge here is in the ability to make the design reusable and relocatable for the different site conditions. For instance, beams that were used in an area with a narrow distance between the sidewalk and the street curb cannot be reused in an area with a wide distance. Additionally, the structural plank forming the slab may need to be trimmed or resized to fit in the new location. The second option, a metallic pad, provides a more adaptable design since it could be resized as needed. Telescopic ramps, commonly used for wheelchairs, potentially could be used as bus stop pads. However, since they are designed for carrying only one wheelchair at a time, they require significant modifications to accommodate passengers boarding the bus.

Maintenance of traffic, a major cost item, possibly could be eliminated when the granular base would not have to be compacted using heavy machinery. However, the granular base would have to be traditionally compacted to ensure minimum settlement over the pad's service life. Instead of adopting traditional slab-on-grade design, one method for eliminating the granular base compaction is to adopt a beam design concept where a system of beams bridges the gap between the sidewalk and the street curb. The proposed design alternatives, therefore, have four main components: 1) foundation, 2) supporting beam, 3) slab, and 4) connections. Figure 2 illustrates a preliminary design concept of the proposed bus stop pads.

FIGURE 2. proposed bus stop pads

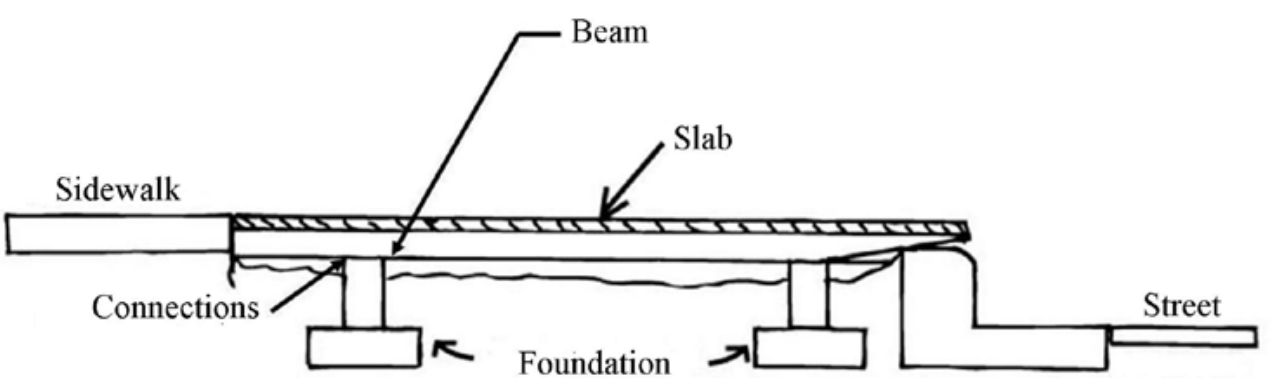

\section{Foundation}

The foundation of the pad is one of the most important design considerations. The foundation is directly exposed to soil, which could contain many acidic and corrosive materials. As such, the foundation is designed using concrete materials; concrete has a high compressive-strength-to-price ratio and provides very good chemical resistance. 
Compared to concrete, polymeric materials or thermoplastics provide greater durability; however, they are more expensive and have lower compressive strength. Their lower strength also results either in a larger foundation profile or an increase in the size needed to withstand foot and wheelchair traffic. Hence, more soil would need to be excavated, increasing the construction cost. For these reasons, concrete is chosen as an appropriate material for the foundation.

There are several types of footings that can be used for the proposed pads. Their selection depends on the applied load and allowable soil bearing capacity. Since the applied load on the bus stop pad is minimal, any shallow foundation that is readily-available in the market can be adopted. Figure 3a shows a precast pier block that provides a floating foundation for an outdoor deck. The advantage of using this readily-available product is its cost and availability. The precast pier block can be purchased from any home improvement store for as little as $\$ 7.50$ per block. For a $5^{\prime} \times 8^{\prime}$ pad, only four precast pier blocks are needed to support two beams at each end, and the total cost for the foundation is only $\$ 30$. Another advantage of this product is its light weight; each block weighs only $45 \mathrm{lbs}$ and can be handled by one person.
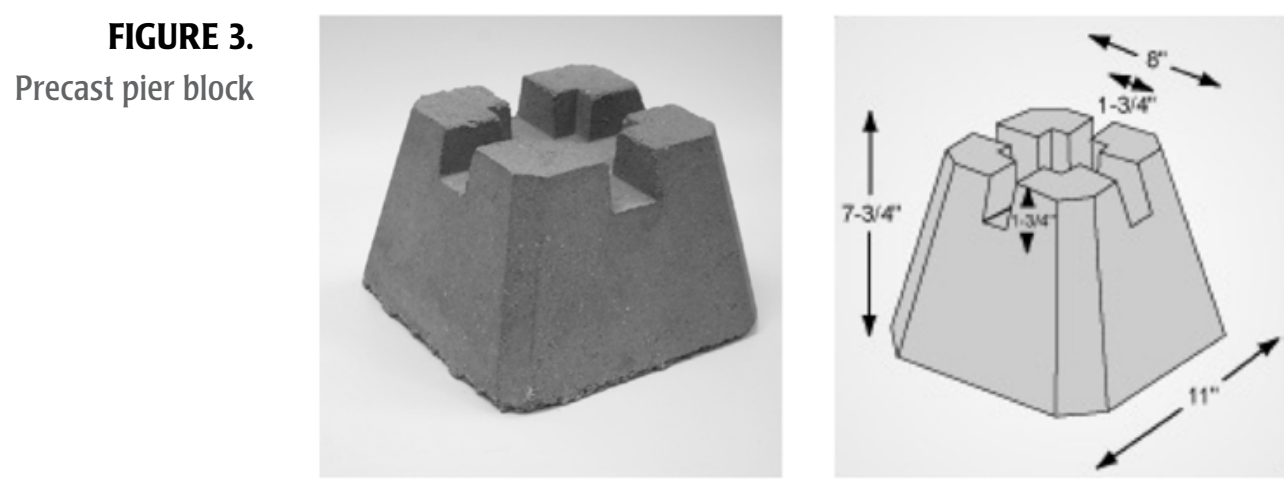

a) Precast pier block (DekBrands 2013)

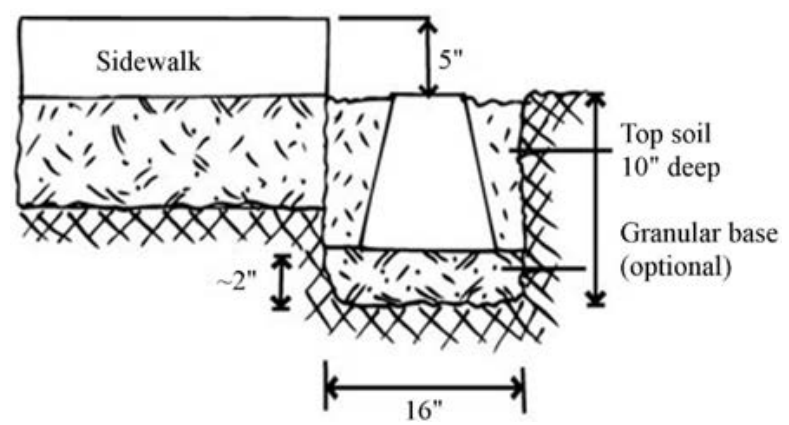

b) Precast pier block installation

To adopt this foundation for bus stop pads, the precast pier block has to be buried under the ground such that there is a clear distance of $5^{\prime \prime}$ from the top of the sidewalk concrete slab to the top of the precast pier block, as shown in Figure 3b. A preliminary design of 
the foundation suggested that the excavated hole should be $16^{\prime \prime}$ in diameter and 10 " in depth. Depending on the site conditions, a 2" thick granular base consisting of No. 57 stone could be placed beneath the precast pier block to minimize the effect of soil settlement and to ensure that the foundation is leveled. Also, due to the small foundation profile, the granular base does not have to be compacted using heavy machinery. The precast pier block is then placed on top of the granular base and covered with top soil that was excavated from the hole. As shown in Figure 4, a portion of the soil along the trajectory of the beam also has to be excavated since the site needs a level surface. As stated previously, this analysis assumed that minimal site preparation would be required.

FIGURE 4. Soil excavation profile

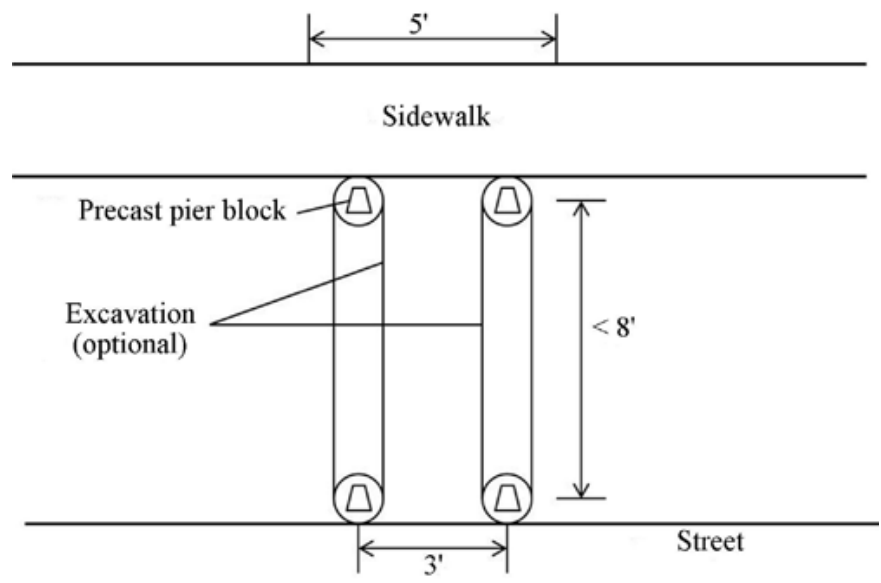

(a) Plan

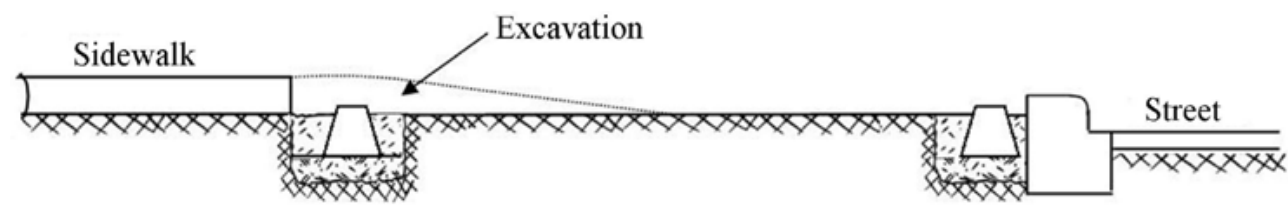

b) Elevation

\section{Plastic Lumber Pad}

A plastic lumber pad consists of three components: supporting beams, slabs, and connectors. To make the design more adaptable to different site conditions, the beam is designed to be of variable length. Further, interlocking beams and telescopic beams are proposed, as shown in Figure 5 . The interlocking beam is built by bolting multiple beams with the same cross-section together. The telescopic beam uses beams with different cross-sections; the beam with a smaller cross-section slides into the beam with a larger cross-section. The advantage of the telescopic beam is that it is more adaptable to different site conditions, whereas the interlocking beam will be limited to the preconfigured dimensions. However, the advantage of the interlocking beam lies in the span length. If the distance between the sidewalk and the street curb is significant, then the only option is to use the interlocking beam. Another advantage of the interlocking beam is that even at a shorter span length, 
the interlocking beam generally has a lower profile and, therefore, less soil needs to be excavated. Note that both beams are connected using structural bolts.

FIGURE 5.

Plastic lumber pad
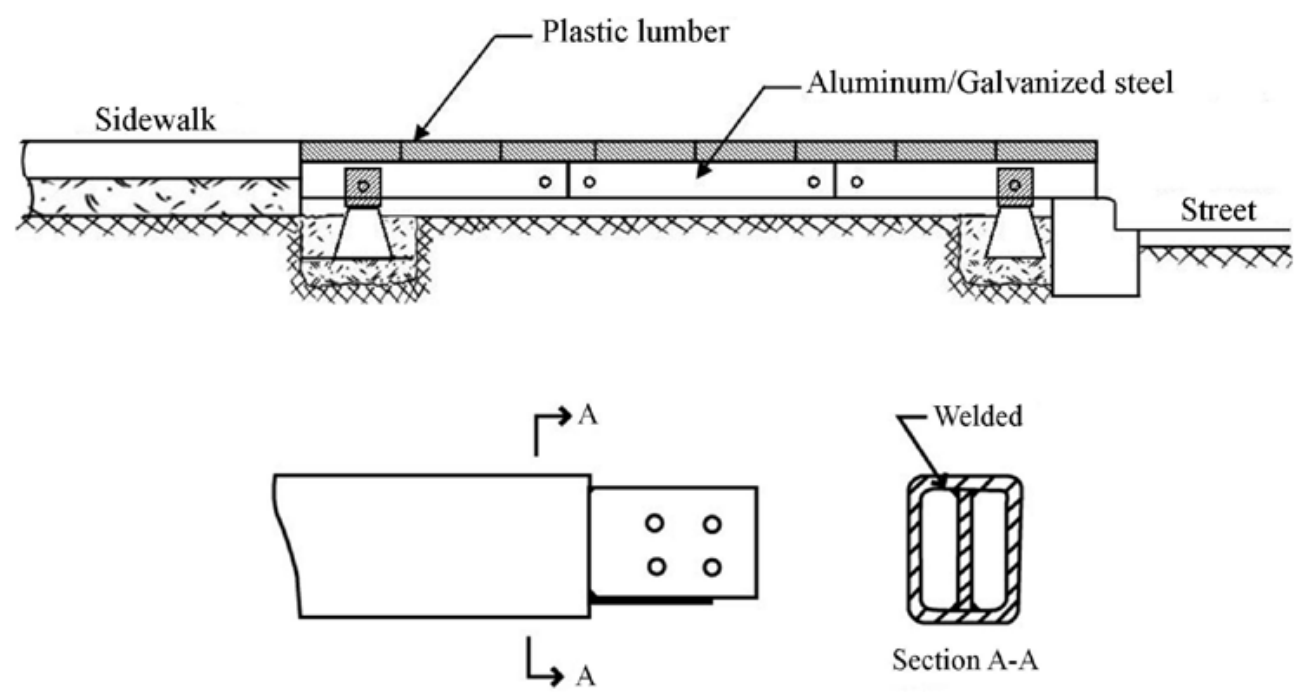

Section A-A

a) Using interlocking beams concept
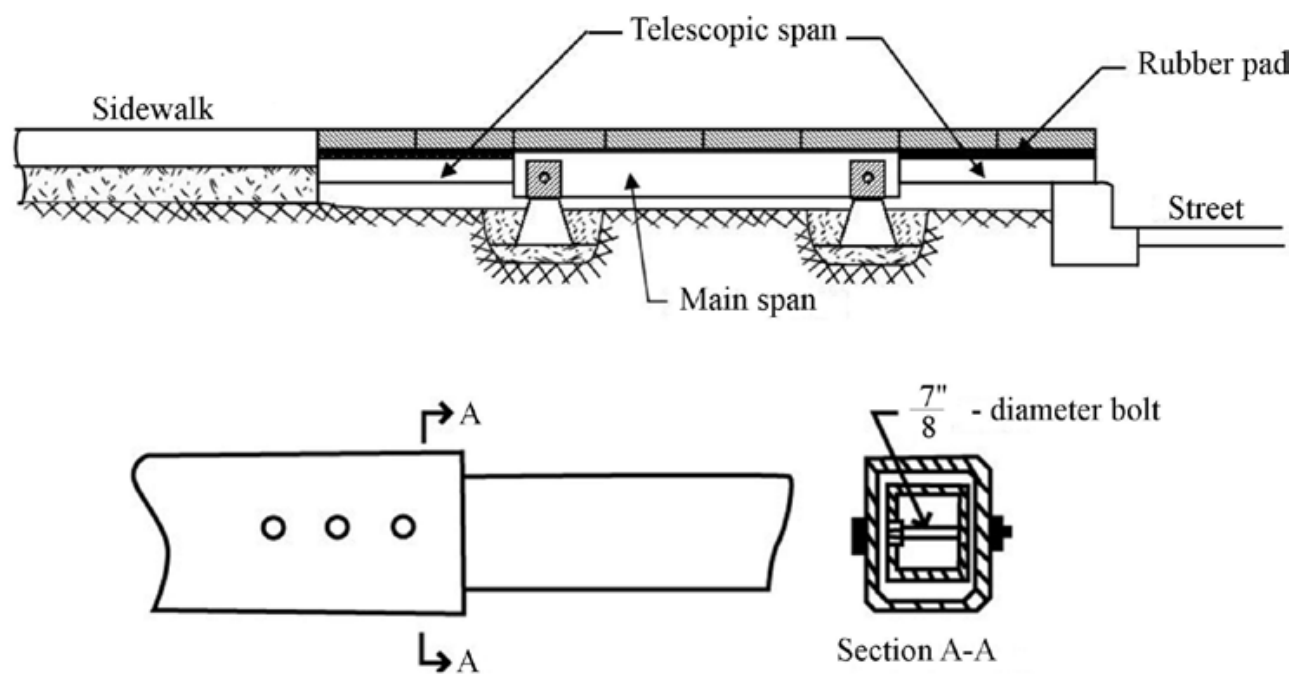

b) Using telescopic beams concept

\section{Supporting Beam}

The supporting beam needs to have high flexural strength-to-weight ratio for it to be relatively shallow and to minimize soil excavation. Either steel or aluminum can be used as supporting beams. However, one problem with steel is corrosion, so it has to be either painted or galvanized to protect it from corrosion. Hot-dip galvanized steel extends the service life to 50 years, and the process is relatively cheap compared to painting. On the other hand, aluminum does not corrode, yet it could be more expensive as more material is needed to compensate for its lower stiffness. Since aluminum is approximately two to 
three times costlier than steel and also is more susceptible to theft, galvanized steel is recommended for building the supporting beams for the bus stop pads.

\section{Slab}

The slab is directly exposed to the harsh environment and has to withstand foot and wheelchair traffic. Therefore, the slab must be designed such that it is durable and slip-resistant. Several materials, including reinforced concrete, nonslip steel deck, timber deck, and plastic lumber deck, could be considered. Of these materials, plastic lumber is the most economical option when life cycle cost of the deck is considered. Plastic lumber is relatively cheap at $\$ 8$ per linear foot for a $2^{\prime} \times 8^{\prime}$ plank. It is very durable, and most manufacturers offer a 50-year limited warranty. Plastic lumber also comes in multiple colors and textures, which allows it to blend into the surrounding environment, resulting in aesthetically-pleasing bus stop pads.

For the above-mentioned reasons, plastic lumber is used to build the slab and is bolted to the beam using four bolts. The beam had slotted holes predrilled at constant intervals of approximately $3^{\prime \prime}$ to create the flexibility to slide the slab back and forth and to slightly rotate the slab. The rotation of the slab is a very important design concept because not all sidewalk edges are parallel to the street edges.

Additionally, the slab can be installed with small gaps (not more than $1^{\prime \prime}$ ) to ensure that the slab fits in the available spaces. Half-inch gaps are acceptable, as they comply with ADA requirement of $1 / 2^{\prime \prime}$ maximum gratings. If a larger gap is needed, particularly when the slab has to be rotated, the gap could simply be filled with rubber materials, which can eliminate gratings from the surface.

\section{Connections}

A connection had to be designed to attach the supporting beam to the foundation. Additionally, the slab also had to be bolted down to the supporting beams. Galvanized steel brackets and bolts are used for this application because the supporting beam is recommended to be built with galvanized steel. Further, there is no additional benefit if the connections are more durable than the main supporting structure.

To minimize the effect of moment on the precast pier block, a custom steel bracket is fastened to the top of the precast pier block, as illustrated in Figure 6. The custom steel bracket is composed of a 5/16" $\times 3^{\prime \prime} \times 3^{\prime \prime}$ base plate and two $3 / 16^{\prime \prime} \times 3^{\prime \prime} \times 3-1 / 4^{\prime \prime}$ side plates welded together to form an oversized channel to support the steel beam. The steel beam is mounted on the oversized channel using a Group A bolt 5/8" in diameter. The oversized channel also is anchored at the top of the precast pier block using a concrete anchoring bolt $5 / 8^{\prime \prime}$ in diameter. 
FIGURE 6.

Group A

Group A

Customized steel bracket
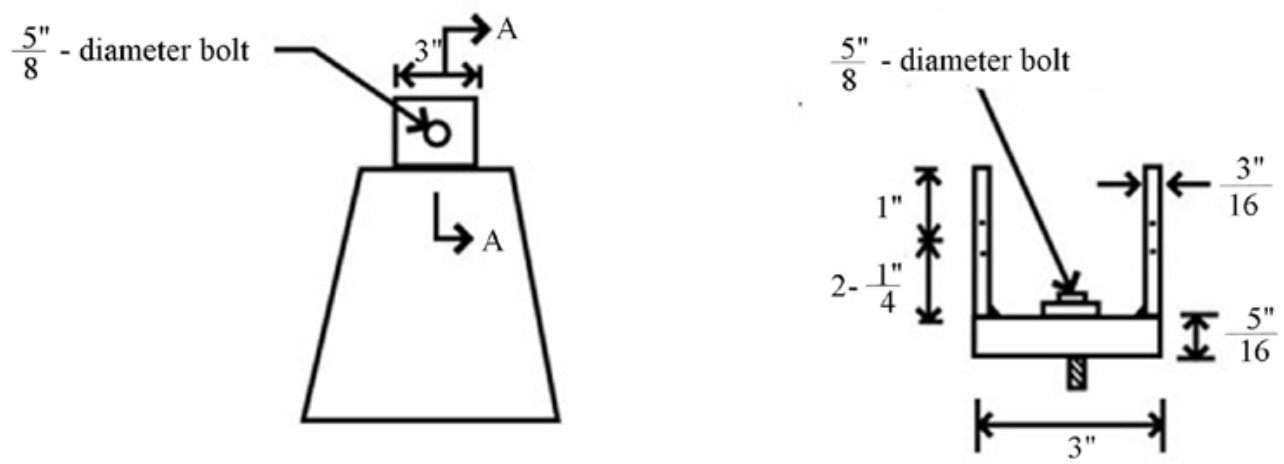

\section{Metallic Pad}

Although the plastic lumber pad presented a cost-effective solution for bus stop pads, it is labor-intensive and time-consuming, particularly in laying the slab and measuring the appropriate gaps. Alternatively, a metallic pad could be used to minimize the need to lay down various components. This option, as shown in Figure 7 , is similar to the telescopic ramp, but with higher load resistance. The metallic pad consisted of two components, where a smaller component (Section B-B in Figure 7) slides into the larger component (Section A-A in Figure 7). Because of its size, these components had to be made of lightweight materials, such as aluminum or high strength steel, which have a high strength-to-weight ratio.

FIGURE 7.

Metallic pad

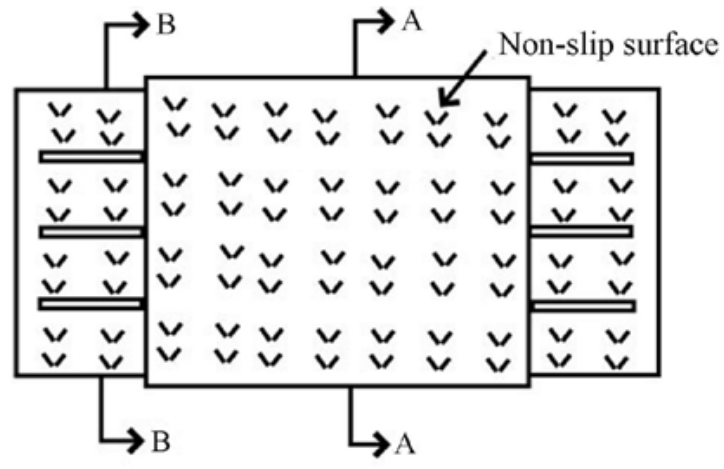

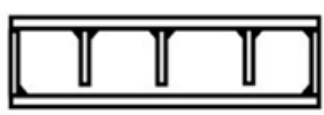

Section A-A

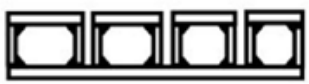

Section B-B

The advantage of this design concept is that after the contractor lays the foundation, the contractor only has to mount the larger component and then slide the smaller component to the sidewalk and the street and lock them in place. Removing this system would also be easy, as the contractor only has to unlock the smaller component and disconnect the main component from the footing. The ease and time of installation potentially can allow transit agencies to self-install and self-remove the metallic pad without contracting a third party, which makes it a preferred design alternative for movable pads, particularly during road work or special event. 


\section{Conclusions and Recommendations}

The ADA requires bus stops to be accessible for individuals with disabilities. At a minimum, bus stops must have firm, stable, and slip-resistant loading pads. To meet the ADA requirements, bus stops typically are constructed with concrete or asphalt loading pads. The construction of concrete/asphalt loading pads is costly, and their relatively long construction periods are disruptive to traffic and abutting businesses. In this paper, materials that could be used to construct movable bus stop loading pads were reviewed and evaluated. Based on the evaluation, two design alternatives, plastic lumber pads and metallic pads, were discussed. Construction of bus stop pads using these design alternatives is estimated to take no longer than half a day, unlike the conventional concrete pads which require at least two days.

\section{Potential Design Materials}

A review of the existing materials identified several alternatives that could replace the existing conventional cast-in-place concrete slabs. Six materials were found to be feasible alternatives and were reviewed in detail: 1) concrete/asphalt, 2) metal, 3) rubber, 4) thermoplastic, 5) composite, and 6) wood. These six materials were evaluated based on their structural performance, long-term durability, adaptability, life cycle cost, aesthetics, and safety and accessibility of transit riders with mobility devices.

Of the six materials, plastic lumber and metals were found to have the highest potential to replace conventional design. Plastic lumber is rated highest based on design considerations, material properties, and life cycle cost. It has good strength (although not as high as concrete), and it is also considerably light (although not as light as Mobi-mat). Plastic lumber is also one of the cheapest and most durable systems.

\section{Design Alternatives}

Two design alternatives, plastic lumber pad and metallic pad, were proposed for further investigation. These new design alternatives are anticipated to minimize maintenance of traffic and the need for heavy machinery to excavate, fill, and/or compact the soil. The plastic lumber pad provides the most cost effective solution and has the potential to replace conventional concrete/asphalt pads. The metallic pad is a more expensive option but does provide significant cost saving in term of time and labor and, hence, is recommended for transit agencies with frequent bus route changes. The ease of installation of the metallic pad also allows transit agencies to install and remove the pads using internal support staff.

Both alternatives rely on the concept of bridge construction and consist of four major components-foundation, slab, beam, and connections. The foundation for both alternatives consists of four or more precast pier blocks that are buried underground to provide the support for the superstructure. The foundation is a readily-available precast concrete pier block that can be purchased from any home improvement store. The connections are made of metallic (galvanized steel or stainless steel) U-brackets and attach the foundations to either the plastic lumber beam or the metallic pad.

The difference between the two alternatives (plastic lumber pad and metallic pad) lies in the slab and beam components. There are two design concepts for the beams in the 
plastic lumber design option, namely, interlocking beams and telescopic beams. The telescopic beam concept is proposed to provide faster installation time. A plastic lumber slab consists of several plastic lumber planks placed side-by-side on top of the plastic lumber beams. In lieu of the beam and slab, a metallic pad relies on using a single superstructure component consisting of two telescopic parts that slide into each other. The advantage of a metallic pad lies in its construction speed, while a plastic lumber pad design is cheaper and can span farther.

\section{Acknowledgments}

This research was funded by the Research Center of the Florida Department of Transportation (FDOT). The authors are grateful to Ms. Diane Quigley and Ms. Gabrielle Matthews of the FDOT Public Transit Office for their project support and guidance.

\section{References}

DekBrands. 2013. Dek-Block pier specifications. http://www.deckplans.com/ dek-block-specifications, accessed July 2013.

Deschamps. 2013. Mobi-Mat RecPath. http://www.mobi-mat-chair-beach-access-dms. com/prod_recpath.php, accessed June 2013.

Florida Department of Transportation (FDOT). 2011. Specifications and estimates. http:// www.dot.state.fl.us/specificationsoffice/Estimates/HistoricalCostInformation/HistoricalCost.shtm, accessed May 2013.

Suksawang, Nakin, Albert Gan, Priyanka Alluri, Kirolos Haleem, Katrina Meneses, Fabian Cevallos, and Dibakar Saha. 2013. Analysis of movable bus stop boarding and alighting areas. Final Report BDK80 977-23, Florida Department of Transportation, Tallahassee, FL.

U.S. Access Board. 2006. A guide to ADAAG provisions. http://www.access-board.gov/ guidelines-and-standards, accessed April 2013.

Wu, Wanyang, Albert Gan, Fabian Cevallos, and David Shen. 2011. Selecting bus stops for accessibility improvements for riders with physical disabilities. Journal of Public Transportation, 14(2): 133-149.

\section{About the Authors}

Nakin Suksawang, Ph.D., P.E. (nsuksawang@fit.edu) is an Assistant Professor in the Department of Civil Engineering at the Florida Institute of Technology. He holds a Ph.D. in Structural Engineering from Rutgers University. His research interests include advanced structural materials, concrete durability, structural health monitoring and structural safety and reliability.

Priyanka Alluri, Ph.D., P.E. (palluri@fiu.edu) is a Research Associate at the Lehman Center for Transportation Research, Florida International University. She received her 
M.S. and Ph.D. degrees in Civil Engineering from Clemson University in South Carolina in 2008 and 2010, respectively. Her research interests include public transit, traffic safety, crash data analysis, and ITS.

Albert Gan, Ph.D. (gana@fiu.edu) is a Professor in the Department of Civil and Environmental Engineering at Florida International University. He holds a Ph.D. in Civil (Transportation) Engineering from the University of Florida. His research interests include public transit, highway safety, ITS, and transportation software applications.

Katrina Meneses, M.S. (kmeneses@fiu.edu) was a Graduate Research Assistant with the Department of Civil and Environmental Engineering at Florida International University. She earned her bachelor's and master's degrees in Civil Engineering from Florida International University in 2012 and 2013, respectively. At FIU, she worked on several research projects in traffic safety and public transportation.

Fabian Cevallos, Ph.D. (fabian.cevallos@fiu.edu) is the Transit Program Director at the Lehman Center for Transportation Research, Florida International University. He holds a Ph.D. in Civil (Transportation) Engineering from Florida International University. His research interests include Advanced Public Transportation Systems (APTS), transit planning and operations, traffic safety, driving simulation, business intelligence, and information technology.

Kirolos Haleem, Ph.D., P.E., PTOE (khaleemm@fiu.edu) is a Research Associate in the Department of Civil and Environmental Engineering at Florida International University. He received his master's and Ph.D. degrees in Civil Engineering from the University of Central Florida in 2007 and 2009, respectively. His areas of expertise are traffic safety analysis, statistical modeling and data mining, traffic operations, and ITS.

Dibakar Saha, M.S. (dsaha003@fiu.edu) is a Ph.D. Candidate in the Department of Civil and Environmental Engineering at Florida International University. He obtained his master's degree in Civil Engineering (Transportation) from Bangladesh University of Engineering and Technology in 2010. His research interests include traffic safety, transportation planning, and data analysis. 